\title{
Corrossion Behavior of Ni-W-P Coating in Hypersaline Brine
}

\author{
Shao Qianqian \\ School of Environmental Science and Engineering \\ Shandong University \\ Jinan ,China \\ wshshqq@126.com
}

\author{
Zhang Xin \\ School of Environmental Science and Engineering line \\ Shandong University \\ Jinan ,China \\ Zhangxin072952492@126.com
}

\author{
Cui Zhaojie \\ School of Environmental Science and Engineering line \\ Shandong University \\ Jinan ,China \\ cuizj@sdu.edu.cn \\ Tan Xianfeng \\ Shandong Provincial Lubei Geo-engineering \\ Exploration Institute \\ Dezhou,Chinaline \\ Geotan1977@126.com
}

\begin{abstract}
To improve the corrosion resistance of N80steel, Ni-W-P coating was prepared by electroless deposition. The corrosion properties for $\mathrm{Ni}-\mathrm{W}$-P coating were investigated in hypersaline ground brine. Results of weight loss tests show that the corrosion resistance of the $\mathrm{Ni}-\mathrm{W}$-P coating is $\mathbf{1 0}$ times of N80steel in hypersaline brine at $90{ }^{\circ} \mathrm{C}$. Electrochemical tests show that the current density of Ni-W$P$ coated sample reduce from $7.94 \times 10^{-2} \mu \mathrm{A} / \mathrm{cm}^{2}$ to $4.28 \times 10^{-3}$ $\mu \mathrm{A} / \mathrm{cm}^{2}$, and the corrosion potential changes from $-0.700 \mathrm{~V}$ to $-\mathbf{0 . 3 9 8} \mathrm{V}$ compared with N80steel. Scanning electron microscopy (SEM) micrographs and X-ray photoelectron spectroscopy (XPS) were used to evaluate the morphology and composition of the corrosion layer of $\mathrm{Ni}-\mathrm{W}$-P coating. The results show that severe intergranular corrosion appear in N80steel, whereas no intergranular corrosion occur in Ni$W-P$ coating. The chemical composition of the corrosion layer of $\mathrm{Ni}-\mathrm{W}-\mathrm{P}$ coating is $\mathrm{NiO}, \mathrm{WO}_{3}$, phosphate, and hypophosphite which led to superior corrosion resistance in hypersaline brine. This study confirms that the Ni-W-P coating can be applied for corrosion protection in hypersaline environment.
\end{abstract}

Keywords-Ni-W-P coating; hypersaline brine; corrosion; corrosion resistance;corrosion layer;

\section{INTRODUCTION}

Nowadays, the demand for lithium is increasing because batteries, specifically electric vehicles, require a good deal of lithium resources. Previous research has reported that lithium resources mainly exist in salt lakes and ground brine [1]. Brine resources that are rich in lithium are abundant in China. Exploitation of brine resources has much value for the economy and society. However, brine resources, specifically ground brine resources with high salinity, cause serious corrosion in equipment and materials during brine exploitation and transportation processes. Therefore, studies on anticorrosion coatings to prevent metal loss, reduce energy consumption, and ensure continuous mining of brine are extremely significant.
Nickel (Ni) is highly resistant to corrosion in many corrosive media, and its resistance can be highly improved by adding copper $(\mathrm{Cu})$, chromium $(\mathrm{Cr})$, molybdenum (Mo), or tungsten (W). Some researchers have reported that $\mathrm{Ni}-\mathrm{Cu}$ and $\mathrm{Ni}-\mathrm{Cr}-\mathrm{Fe}-\mathrm{Mo}$ alloys have good corrosion resistance in brine and acid solution, specifically, immunity to chloride ion stress corrosion [2]. The composite coatings of electrolessly plated Ni-P have been successfully applied in chemical, mechanical, and other industries because of their excellent properties such as corrosion resistance, wear resistance, low friction, and environmental friendliness [3].Compared with $\mathrm{Ni}-\mathrm{P}$ coatings, electroless $\mathrm{Ni}-\mathrm{W}-\mathrm{P}$ coatings have higher wear resistance and corrosion resistance because of the incorporation of the third element $\mathrm{W}$ into $\mathrm{Ni}-\mathrm{P}-$ based coating, which significantly influences the amount of grain boundary diffusion paths offered by the nanostructure, thus promoting the formation of the tungsten oxide film on the coating surface [4]. Many researchers have studied the corrosion behavior of Ni-Pbased composite coatings in hydrochloric acid and sodium chloride solutions $[5,6]$. The wear behavior of electroless Ni-P and Ni-W-P coatings was also studied by Palaniappa et al. [7]. The results showed that coatings with high tungsten content exhibit very good wear resistance. In the study of corrosion wear mechanism of Ni-W-P coating in $3.5 \%$ chloride solutions solution, a synergy effect between wear and corrosion was found to exist in Ni-W-P coating [4]. The Ni-W-P coating shows the highest resistance among the investigated coatings. The corrosion behavior of Ni-W-P in hydrochloric acid, sulfuric acid, and sodium chloride solutions was also studied $[8,9]$. However, only a few studies on the corrosion behavior of Ni-W-P coating in high-salinity brine coming from the deep level of ground have been conducted.

In this paper, the corrosion behaviors of Ni-W-P coating and N80steel were explored by electrochemical polarization measurements in $265 \mathrm{~g} / \mathrm{L}$ hypersaline ground brine. In addition, immersion tests were carried out in 
hypersaline ground brine at $90{ }^{\circ} \mathrm{C}$ for $\mathrm{Ni}-\mathrm{W}-\mathrm{P}$ coating and N80steel samples for 15 days to identify the type of corrosion scale formed and the microstructure and morphology of the samples after corrosion.

\section{EXPERIMENTAL PROCEDURE}

The discussed model is given as follow: The composition of the basic bath used for the ternary Ni-W-P alloys is given in TABLE I. The Ni-W-P coating was deposited on a vertically suspended N80steel specimen. The N80steel specimen was $50 \mathrm{~mm}$ long and $10 \mathrm{~mm}$ wide. Specimens were first cleaned in $80 \mathrm{~g} / \mathrm{L}$ sodium carbonate solution at $100{ }^{\circ} \mathrm{C}$ for $2 \mathrm{~min}$ and then rinsed in $60{ }^{\circ} \mathrm{C}$ hot water and running deionized water. The degreased samples were deoxidized in $15 \%$ hydrochloric $(\mathrm{HCl})$ acid solution for $20 \mathrm{~s}$, and then rinsed in running deionized water. Specimens were activated in $5 \% \mathrm{HCl}$ solution, rinsed in running deionized water, and placed in the bath for electroless plating. Electroless plating was carried out in a $500 \mathrm{ml}$ glass beaker at $\left(90 \pm 1{ }^{\circ} \mathrm{C}\right)$ for $2 \mathrm{~h}$. After plating, the specimens were again rinsed in running water, dried, and preserved for the following tests.

TABLE I. Composition and operating conditions of the plating baths

\begin{tabular}{cc}
\hline Constituents of plating bath & Concentration \\
\hline Nickel sulphate & $35 \mathrm{~g} / \mathrm{L}$ \\
Sodium hypophosphite & $25 \mathrm{~g} / \mathrm{L}$ \\
Sodium citrate & $100 \mathrm{~g} / \mathrm{L}$ \\
Lacticacid & $5 \mathrm{ml} / \mathrm{L}$ \\
Ammoniumsulfate & $30 \mathrm{~g} / \mathrm{L}$ \\
Sodium tungstate & $40 \mathrm{~g} / \mathrm{L}$ \\
& 9.0 \\
Operating conditions & $90 \pm 1$ \\
\hline
\end{tabular}

A SUPRA $^{\mathrm{TM}} 55$ thermal field emission scanning electron microscope (SEM) with energy dispersive analysis X-ray spectroscope (EDX) attachment was used to determine the surface morphology and elemental compositions of the coatings before and after corrosion. The sample surface analysis of XPS was carried out with X-ray photoelectron spectroscopy (ESCALAB 250). XRD experiment was performed by using Japan D/max-3C automatic X-ray diffraction apparatus with $\mathrm{Cu} \mathrm{K} \alpha$ X-ray source, an accelerating voltage of $40 \mathrm{kV}$, and a current density of $40 \mathrm{~mA} \cdot \mathrm{cm}^{-2}$.

Anodic potentiodynamic polarization in hypersaline ground brine (Salinity=260 g/L) was conducted to study the corrosion behavior of the coatings using a CHI760 electrochemical workstation with a conventional threeelectrode cell. The composition of the brine is given in TABLE II. The reference electrode was saturated calomel electrode (SCE), and the auxiliary electrode was $\mathrm{Pt}$ electrode. All potentials reported in this paper were measured with respect to the SCE. Potentiodynamic polarization curve measurements were performed at potential scan rate of $1 \mathrm{mV} . \mathrm{s}^{-1}$. The potential range was from $-1.5 \mathrm{~V}$ to $1.5 \mathrm{~V}$ versus open-circuit potential (OCP). TABLE II. Composition of the hypersaline brine

\begin{tabular}{ccccccc}
\hline $\begin{array}{c}\text { Constituents } \\
\text { of the brine }\end{array}$ & $\begin{array}{c}\mathbf{N a}^{+} \\
(\mathbf{g} / \mathbf{L})\end{array}$ & $\begin{array}{c}\mathbf{C a}^{2+} \\
(\mathbf{g} / \mathbf{L})\end{array}$ & $\begin{array}{l}\mathbf{M g}^{2+} \\
(\mathbf{g} / \mathbf{L})\end{array}$ & $\begin{array}{c}\mathbf{B a}^{2+} \\
(\mathbf{g} / \mathbf{L})\end{array}$ & $\begin{array}{c}\mathbf{S r}^{2+} \\
(\mathbf{g} / \mathbf{L})\end{array}$ & $\begin{array}{c}\mathbf{C l}^{-} \\
(\mathbf{g} / \mathbf{L})\end{array}$ \\
\hline concentration & 98.39 & 6.77 & 5.26 & 9.23 & 3.37 & 142.69 \\
\hline
\end{tabular}

The weight loss method was applied following the guidelines in ASTM G 31 Standard Practice for Laboratory Immersion Corrosion Testing of Metals. Coupons in the shape of disks having $13.6 \mathrm{~cm}^{2}$ geometrical area were cut and abraded down to grade 120 with emery paper. Previously weighed coupons were suspended and immersed in the original brine solutions. Each container held three coupons. The containers were kept at a temperature of $90{ }^{\circ} \mathrm{C}$. The coupons were withdrawn at different time periods. The corrosion products were then stripped by immersion in $1 \mathrm{~mol} \mathrm{dm}^{-3}$ hydrochloric acid. Subsequently, the coupons were neutralized and rinsed, first with a saturated sodium carbonate solution and then with distilled water, to be finally dried and re-weighed.

\section{RESULTS AND DISSCUSION}

\section{1) Coating morphology and composition}

The thickness of the electroless Ni-W-P coatings in this investigation was around $15 \mu \mathrm{m}$. Fig. 1 shows a typical Xray diffractogram obtained for the electroless deposition of Ni-W-P layers. The diffractogram displayed a broad peak at around $2 \mathrm{~T}=45^{\circ}$, indicating that amorphous $\mathrm{Ni}-\mathrm{W}-\mathrm{P}$ coatings were successfully obtained. This result is in agreement with the report of Pedro de Lima-Neto [10]. Chemical compositions of the Ni-W-P coating determined by EDX are shown in TABLE III. The Ni-W-P coating consisted of $86.69 \mathrm{at} \% \mathrm{Ni}, 2.1 \mathrm{at} \% \mathrm{~W}$, and $11.21 \mathrm{at} \% \mathrm{P}$. Many researchers have reported that the crystallization behavior and microstructure properties of electroless deposition Ni-P coatings depend on the phosphorus contents [11]. The as-deposited coating was fully amorphous when the phosphorous content was more than $11 \%$ [9]. Fig. 2 reveals the surface morphologies of Ni-WP. The SEM photographs display that the surface morphology of the Ni-W-P coating was a homogeneous and compact layer without microcracks.

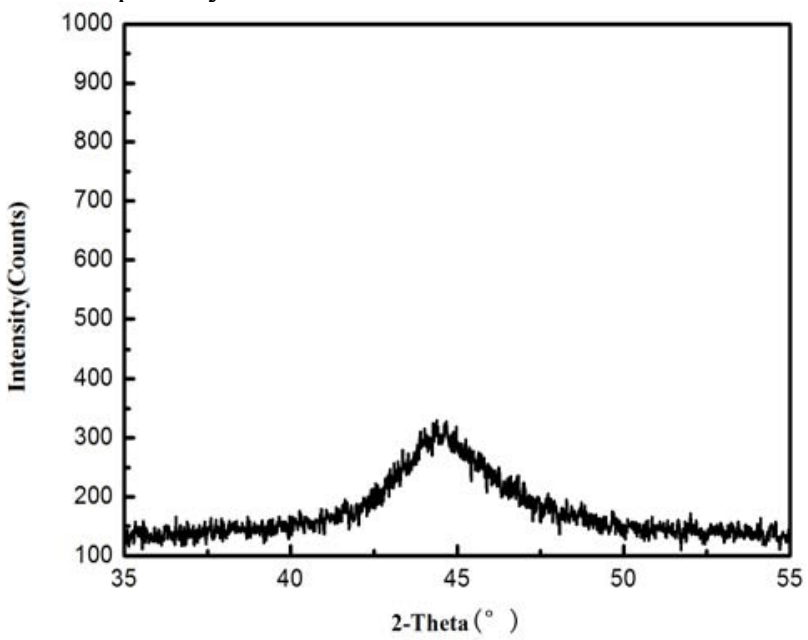

Figure 1. Typical X-ray diffractogram obtained for electroless deposition of Ni-W-P layers. 


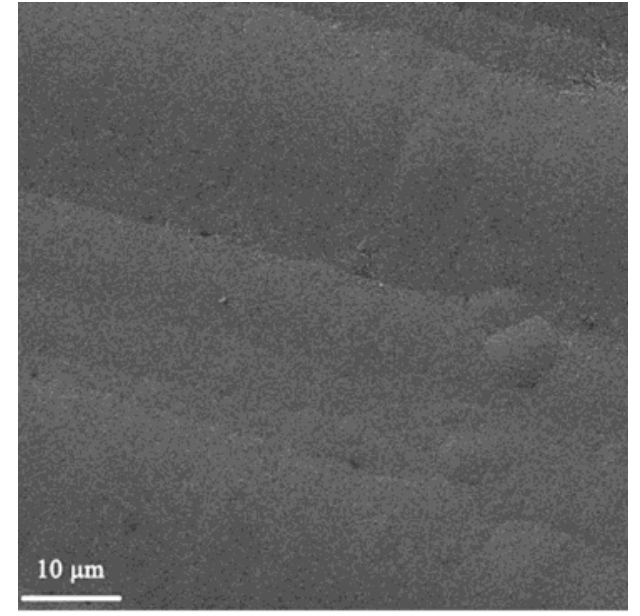

Figure 2. SEM micrographs of electroless deposition of Ni-W-P layers

TABLE III. Chemical composition of Ni-W-P ternary alloy determined by EDX analysis

\begin{tabular}{cc}
\hline Chemical element & composition (at\%) \\
\hline $\mathrm{Ni}$ & 86.69 \\
$\mathrm{~W}$ & 2.1 \\
$\mathrm{P}$ & 11.21 \\
\hline
\end{tabular}

\section{2) Corrosion rate measurement}

The corrosion behavior of the Ni-W-P coatings and N80steel was measured in hypersaline brine at $90{ }^{\circ} \mathrm{C}$ with an immersion weight loss technique for various immersion periods (0-15 days). Fig. 3 shows a typical corrosion behavior of N80steel before and after plating Ni-W-P composite coatings in high hypersaline brine at $90{ }^{\circ} \mathrm{C}$. The weight loss $\mathrm{W}_{\text {loss }}\left(\mathrm{mg} / \mathrm{cm}^{2}\right)$ of the Ni-W-P coating was about 10 times that of the N80steel, indicating that after plating with $\mathrm{Ni}-\mathrm{W}-\mathrm{P}$ coatings, the N80steel had a much lower corrosion rate than the raw N80steel. The corrosion mechanism of N80steel has been clarified but the effect of Ni-W-P coating on the corrosion rate remains complex. Many amorphous metals reportedly exhibit excellent corrosion resistance [12]. In this study, the Ni-W-P coating plated on N80steel had the amorphous structure of Ni-W-P coatings (Fig. 1), which can explain its good corrosion resistance. Moreover, the surface of the N80steel became smooth after being plated with Ni-W-P coating, which directly reduced the contact area between the material and the brine medium. Less contact area meant less metal corrosion loss.

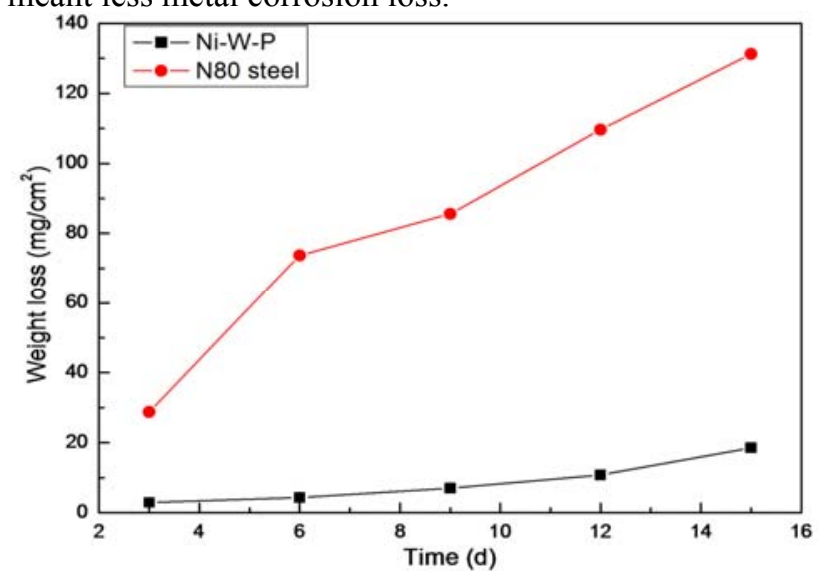

Figure 3. Comparison of corrpsion behavior of N80steel before and after coating $\mathrm{Ni}-\mathrm{W}-\mathrm{P}$

\section{3) Electrochemical behavior}

Fig. 4 shows the polarization curves of the N80steel and the Ni-W-P coatings in the hypersaline brine at ambient temperature. The electrochemical corrosion parameters obtained from Tafel polarization curves are tabulated in TABLE IV. The corrosion current density for the Ni-W-P coatings was $4.28 \times 10^{-3} \mu \mathrm{A} / \mathrm{cm}^{2}$, which was much lower than the value for the N80steel $\left(7.94 \times 10^{-}\right.$ $\left.{ }^{2} \mu \mathrm{A} / \mathrm{cm}^{2}\right)$. The Ni-W-P coating increased the corrosion potential by $300 \mathrm{mV}$ compared with the uncoated sample. The coating sample had a higher surface potential and a lower corrosion current than the substrate, indicating an improved anodic protection for N80steel in hypersaline brine atmosphere [13]. Ni-W-P coating sealed the microcracks and surface pores on N80steel, thus deflecting the infiltration of aggressive ions such as $\mathrm{Cl}^{-}$to the substrate. Moreover, the rapid formation of a highly protective passive film that was uniform and stable caused the high corrosion resistance of the Ni-W-P coating. Generally, the corrosion resistance of any alloy coating depends on the speed of formation of a protective film on the surface [14]. Phosphorus can increase the corrosion potential of Ni-W-P coating and decrease the corrosion current; it encourages the cathodic and anodic reactions during the process of corrosion, hence increasing the anodic dissolution of nickel. The accelerated corrosion of nickel allows the gathering of phosphorus, leading to the formation of stable intermediate compounds such as $\mathrm{Ni}_{3} \mathrm{P}$ and $\mathrm{Ni}_{\mathrm{x}} \mathrm{P}_{\mathrm{y}}$.

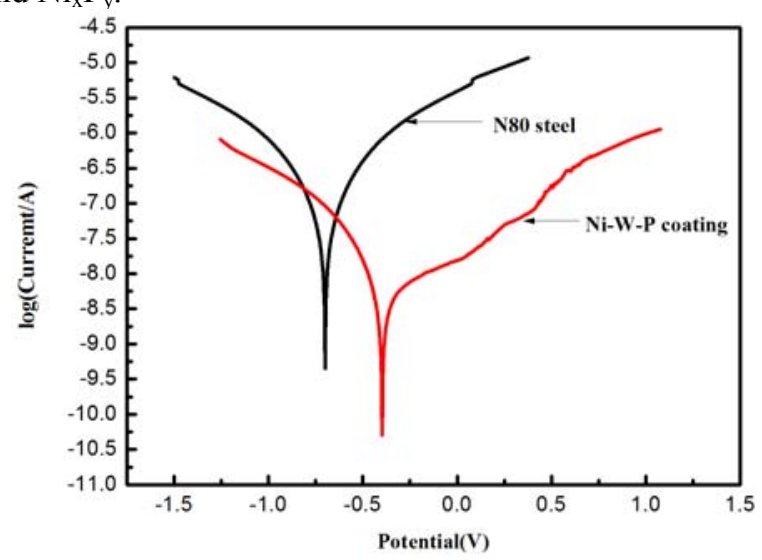

Figure 4. Potentiodynamic polarization curves of the N80steel before and after coatings obtained in high salty brine (Salinity $=260 \mathrm{~g} / \mathrm{L}$ )

TABLE IV. Corrosion characteristics of as plated electroless Ni-W-P coatings and N80steel in hypersaline brine

\begin{tabular}{ccc}
\hline Metal & $\begin{array}{c}\mathbf{E}_{\text {corr }}(\mathbf{V} \text { vs. } \\
\text { SCE })\end{array}$ & $\mathbf{i}_{\text {corr }}\left(\boldsymbol{\mu} \mathbf{A} / \mathbf{c m}^{2}\right)$ \\
\hline N80steel & -0.700 & $7.94 \times 10^{-2}$ \\
Ni-W-P & -0.398 & $4.28 \times 10^{-3}$ \\
\hline
\end{tabular}

\section{4) Microstructural characterization}

Fig. 5 demonstrates the microphotographs for N80steel and electrolessly plated Ni-W-P on N80steel after immersion corrosion in the hypersaline brine (Salinity $=260 \mathrm{~g} / \mathrm{L}$ ) at $90^{\circ} \mathrm{C}$ for 15 days. Fig. 5a shows the microstructure of the surface of N80steel after immersion corrosion for 1 week. The N80steel was so corroded that the surface became rough and loose and cracks appeared on it. However, a small pit without cracks appeared on the 
Ni-W-P coating (Fig. 5b). Figs. 5c and 5d show the surface of N80steel and Ni-W-P coating after immersion corrosion for 2 weeks, respectively. A cracked surface film with a laminar structure was obvious on the corroded N80steel sample. The Ni-W-P coating became slightly rough, but it had no cracks and big pits or a laminar structure. The Ni-W-P coating showed such good corrosion resistance because of the high homogeneity of the amorphous structure that contributed to immunity from pitting corrosion and the absence of cracks; the presence of cracks would lead to serious corrosion of the material in the aggressive medium. The mentioned results, which were consistent with the weight loss tests and were evaluated by the polarization curves of potential sweep methods, further support the conclusion that the anticorrosive ability of N80steel can be promoted by electroless plating Ni-W-P.
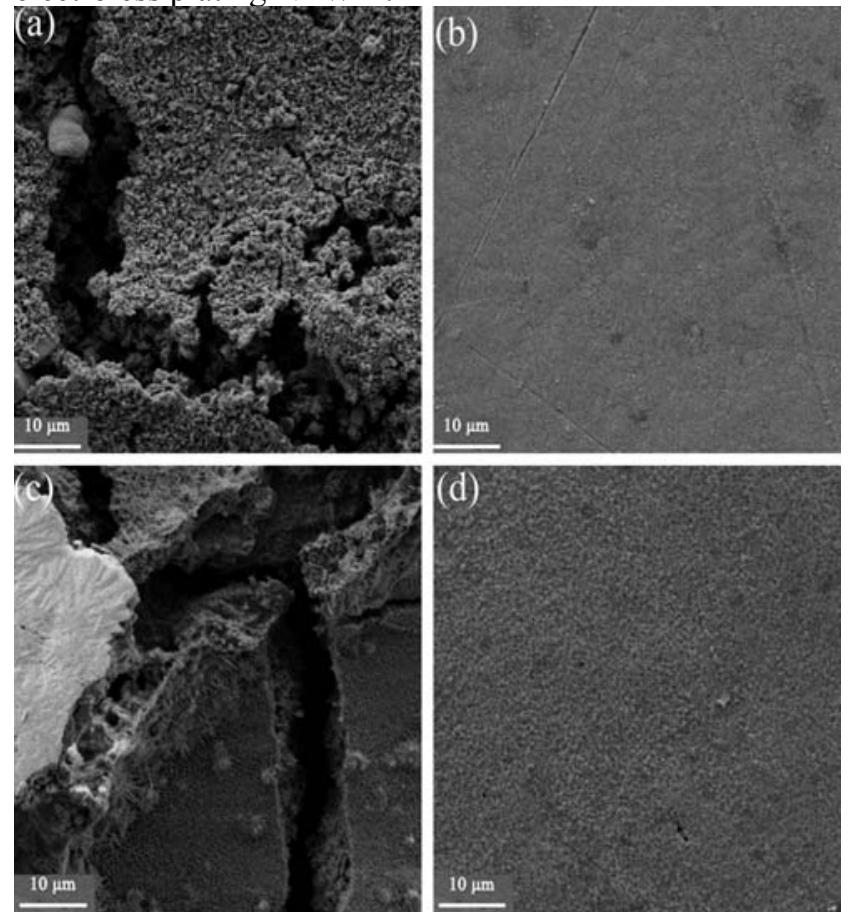

Figure 5. SEM micrographs of N80steel and Ni-W-P deposits after immersion in hypersaline brine at $90^{\circ} \mathrm{C}$ for durations of (a)N80steel 7 days (b) Ni-W-P deposits 7days, (c) N80steel 14 days (d) Ni-W-P deposits 14 days.

\section{5) Analysis of corrosion product}

To clarify the composition of the corrosion scale formed at high temperature on N80steel and Ni-W-P alloy in hypersaline brine, the XPS depth profiles of the N80steel and Ni-W-P after corrosion were determined. Fig.6 and 7 show the result, respectively. Fe, Ni, W, and $\mathrm{P}$ as the elements of interest appeared in the spectrum of the corrosion scale surface. By examining the separation of $\mathrm{Fe}$ $2 p$ peak in the corrosion scale of the N80steel, two peaks at the binding energies of 710.2 and $711.6 \mathrm{eV}$ were revealed, as seen in Fig.6. According to the standard binding energy, the corrosion layer of the N80 steal consisted of $\mathrm{Fe}_{3} \mathrm{O}_{4}, \mathrm{Fe}_{2} \mathrm{O}_{3}$, and $\mathrm{FeOOH}$. The corrosion scale formed on N80steel was mainly composed of $\mathrm{Fe}^{3+}$ oxide because of the existence of oxygen [15-17].

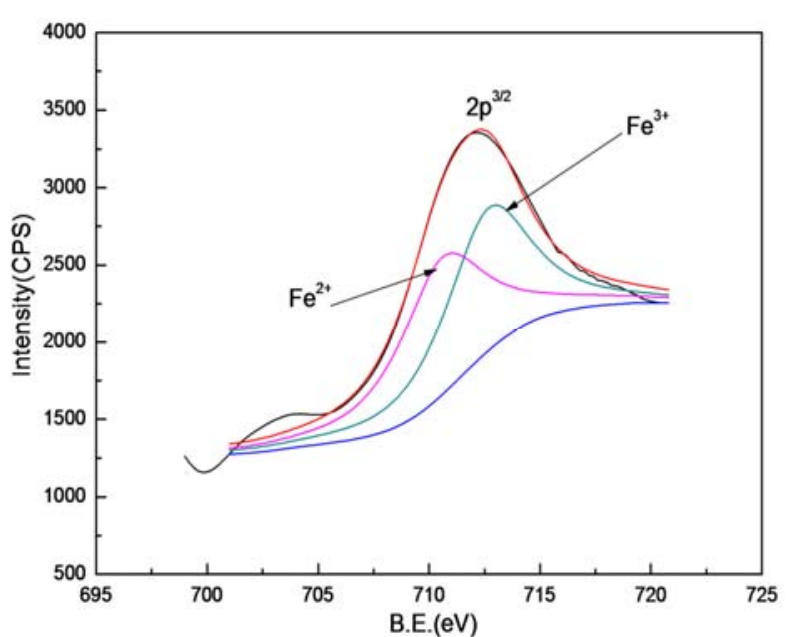

Figure 6. XPS of ion in the oxide on the corroded N80steel specimen

Fig. 7 shows the XPS result of Ni-W-P alloy plating on the N80steel. From Fig. 7a, the Ni 2p peak can separate the three peaks at binding energy of 852.9, 855.6 , and $861.2 \mathrm{eV}$. According to the standard binding energy of nickel compounds, it can be inferred that nickel mainly exists in the form of bivalent and zerovalent in the plating, such as $\mathrm{Ni}(\mathrm{OH})_{2}$ and $\mathrm{Ni}$. In Fig.7c, the $\mathrm{P} 2 \mathrm{p}$ spectra contain two overlapping peaks that correspond to $\mathrm{P}^{5+}$ at $133.5 \mathrm{eV}$ and $\mathrm{P}^{0}$ at $129.3 \mathrm{eV}$. Fig.7e shows the $\mathrm{W}$ 4f spectra containing the two peaks that correspond to $\mathrm{W}^{6+}$ at 36.2 and $38.1 \mathrm{eV}$. According to the standard binding energy of tungsten compounds, a film of $\mathrm{WO}_{3}$ could form here. These results suggest that the surface of the Ni-W-P coating was a dense layer consisting of $\mathrm{Ni}, \mathrm{NiO}, \mathrm{WO}_{3}$, and phosphate. Fig.7b, 7d, and $7 \mathrm{f}$ show the XPS result of Ni-W-P alloy plating on the N80steel after immersion corrosion in hightemperature hypersaline brine. By examining the separation of $\mathrm{Ni} 2 \mathrm{p}$ peak in the surface of the Ni-W-P coating after corrosion, the changes of $\mathrm{Ni}$ in the plating because of corrosion were revealed. In Fig. $7 b$, the Ni $2 p$ spectra contained three overlapping peaks that corresponded to $\mathrm{Ni}^{2+}$ at $854.4 \mathrm{eV}, \mathrm{Ni}^{3+}$ at $856.0 \mathrm{eV}$, and a shake-up peak at $860.8 \mathrm{eV}$. These results suggest that during immersion corrosion, nickel in the plating changed from $\mathrm{Ni}$ and $\mathrm{Ni}(\mathrm{OH})_{2}$ to $\mathrm{NiO}$ and $\mathrm{Ni}_{2} \mathrm{O}_{3}$. In Fig.7d, the $\mathrm{P} 2 \mathrm{p}$ spectra contained three overlapping peaks that corresponded to $\mathrm{P}^{5+}$ at $133.5 \mathrm{eV}, \mathrm{P}^{3+}$ at 130.2 $\mathrm{eV}$, and $\mathrm{P}^{0}$ at $129.3 \mathrm{eV}$. Compared with Fig.7c, the trivalent compounds of phosphorus emerged, and both $\mathrm{P}^{5+}$ and $\mathrm{P}^{0}$ decreased on the surface of the Ni-W-P coating because of the corrosion. Comparing Fig. $7 \mathrm{f}$ with Fig.7e, a minimal change in tungsten peak was noted after corrosion, and the $\mathrm{W} 4 \mathrm{f}$ spectra still contained two peaks that corresponded to $\mathrm{W}^{6+}$ at $35.1 \mathrm{eV}$ and $37.2 \mathrm{eV}$. It can be inferred that tungsten existed in the form of $\mathrm{WO}_{3}$. No substantial change in tungsten was noted on the coating surface after corrosion. The main composition of the surface on the Ni-W-P coating after corrosion became $\mathrm{NiO}, \mathrm{WO}_{3}$, phosphate, and hypophosphite. MacDougall reported that Ni dissolution and $\mathrm{NiO}$ formation can produce a perfect oxide film that will allow Ni-W-P to have good corrosion resistance. Many researchers have found that the addition of $\mathrm{W}$ can induce passivation. W oxides are thermodynamically stable under these experimental conditions. 

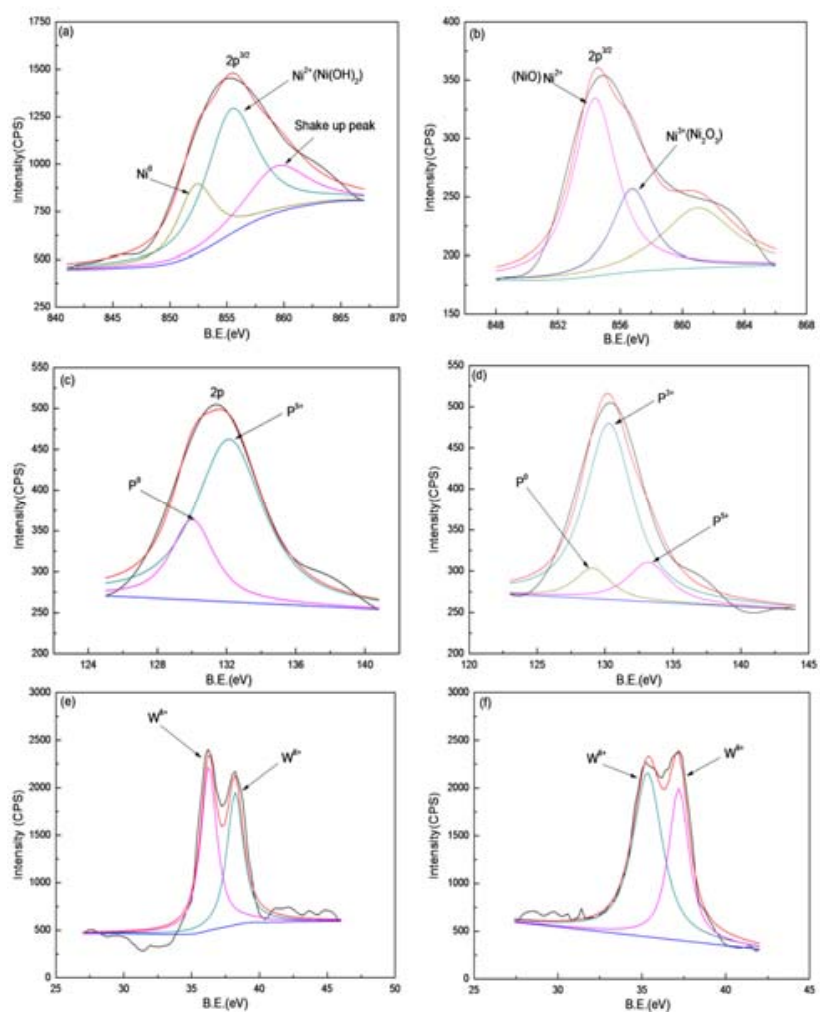

Figure 7. XPS of the element of Ni-W-P coating before (a,c,e) and after (b,d,f)corrosion: (a) (b) nickel, (c)(d) phosphorus, (e)(f) tungsten.

\section{CONCLUSIONS}

Electroless plating of Ni-W-P coating on N80steel was conducted successfully, and it showed quite a high corrosion resistance in hypersaline brine environment. Compared with the uncoated substrate, the current density of the composite Ni-W-P coated sample reduced from $7.94 \times 10^{-2} \mu \mathrm{A} / \mathrm{cm}^{2}$ to $4.28 \times 10^{-3} \mu \mathrm{A} / \mathrm{cm}^{2}$, and the corrosion potential changed from $-0.700 \mathrm{~V}$ to $-0.398 \mathrm{~V}$. During the 15-day immersion test in high-temperature hypersaline brine, the Ni-W-P coating exhibited much less weight loss than N80steel, with the absence of cracking and a minimal damage on the surface. Corrosion resistance of N80steel was greatly improved after the application of electroless deposition of Ni-W-P coating. $\mathrm{NiO}$ and $\mathrm{WO}_{3}$ in the corrosion scale of the electroless deposition of Ni-W-P coating hindered the corrosion paths and prolonged the protection period of coating on the N80steel. Therefore, this study further confirmed that electroless deposition of Ni-W-P coating on N80steel can be used for corrosion protection application in hypersaline brine environments.

\section{ACKNOWLEDGEMENTS}

We acknowledge the financial support for this work by the National High-tech Research and Development Projects (863): The key technology of efficient exploitation of deep brine in the Yellow River delta (Contract No. 2012AA061705).

\section{REFERENCES}

[1] S. E. Kesler, P. W. Gruber, P. A. Medina, "Global lithium resources: Relative importance of pegmatite, brine and other deposits". Ore. Geolo. Rev.vol. 48, Oct. 2012, pp. 55-69, doi:10.1016/j.oregeorev.2012.05.006.

[2] G Lu, G Zangari, "Corrosion resistance of ternary Ni-P based alloys in sulfuric acid solutions", Electrochi. Act, vol. 47, Jul. 2002, pp. 2969-2979, doi:10.1016/S0013-4686(02)00198-6.

[3] H. B. Lee, D. S. Wuu, C. Y. Lee, "Wear and immersion corrosion of $\mathrm{Ni}-\mathrm{P}$ electrodeposit in $\mathrm{NaCl}$ solution", Tribol. Int, vol. 43, Jan. 2010, pp. 235-244, doi: 10. 1016/ j. triboint. 2009.05.031.

[4] F. J. He, Y. Z. Fang, S. J. Jin, "The study of corrosion-wear mechanism of Ni-W-P alloy", Wear, vol. 311, Mar. 2014, pp. 14 20, doi:10.1016/j.wear.2013.12.024

[5] Q. Zhao, Y. Liu, "Comparisons of corrosion rates of Ni-P based composite coatings in $\mathrm{HCl}$ and $\mathrm{NaCl}$ solutions", Corros. Sci, vol. 47, Nov. 2005, pp. 2807-2815, doi:10.1016/j.corsci.2004.11.001.

[6] A. Bai, P. Y. Chuang, C. C. Hu, "The corrosion behavior of Ni-P deposits with high phosphorous contents in brine media", Mater. Chem. Phys, vol. 82, Sep. 2003, pp. 93-100, doi:10.1016/S02540584(03)00193-7.

[7] M. Palaniappa, S. K. Seshadri, "Friction and wear behavior of electroless Ni-P and Ni-W-P alloy coatings", Wear, vol. 265, Aug. 2008, pp. 735-740, doi: 10. 1016/ j. wear. 2008. 01.002.

[8] H. Liu, F. Viejo, R. X. Guo, "Microstructure and corrosion performance of laser-annealed electroless Ni-W-P coatings", Surf. Coat. Technol, vol. 204, Jan. 2010, pp. 1549-1555, doi:10.1016/j.surfcoat.2009.09.074.

[9] H. Liu, R. X. Guo, Y. Liu, "The effect of processing gas on corrosion performance of electroless Ni-WP coatings treated by laser", Surf. Coat. Technol ,vol. 206,Mar. 2012, pp. 3350-3359, doi:10.1016/j.surfcoat.2012.01.039.

[10] P. de Lima-Neto, G. P. da Silva, A. N. Correia, "A comparative study of the physicochemical and electrochemical properties of $\mathrm{Cr}$ and Ni-W-P amorphous electrocoatings", Electrochi. Acta, vol. 51, Jun. 2006, pp. 4928-4933, DOI: 10.1016/j.electacta.2006.01.036.

[11] W. Sha, X. Wu, K. G. Keong, "Electroless copper and nickelphosphorus plating: processing, characterisation and modeling", Elsevier, 2011.pp. 263-274, doi: 10. 1533/9780857090966.1.

[12] S. J. Thorpe, B. Ramaswami, K. T. Aust, " Corrosion and Auger Studies of a Nickel - Base Metal - Metalloid Glass I. The Effect of Elemental Interactions on Passivity in the General Corrosion of Metglass 2826A", Electrochem. Soc, vol. 135,Aug.1988, pp. 21622170, doi: 10.1149/1.2096233

[13] Y. S. Huang, X. T. Zeng, X. F. Hu, "Corrosion resistance properties of electroless nickel composite coatings", Electrochi. Acta, vol. 49, Oct. 2004, pp. 4313-4319, doi:10.1016/j.electacta.2004.04.023

[14] J. N. Balaraju, K. S. Rajam, "Electroless deposition of Ni-Cu-P, Ni-W-P and Ni-W-Cu-P alloys", Surf. Coat. Technol, vol. 195, May. 2005, pp. 154-161. doi:10.1016/j.surfcoat.2004.07.068

[15] H. Subramanian, V. Subramanian, P. Chandramohan, "Role of magnesium ions in reducing high temperature aqueous corrosion of carbon steel". Corros. Sci, vol. 70, May. 2013, pp. 127-139, doi:10.1016/j.corsci.2013.01.021.

[16] D. G. Li, Y. R. Feng, Z. Q. Bai, "Characteristics of $\mathrm{CO}_{2}$ corrosion scale formed on $\mathrm{N} 80$ steel in stratum water with saturated $\mathrm{CO}_{2}$ ", Appl. Surf. Sci, vol. 253, Aug. 2007, pp. 8371-8376, doi:10.1016/j.apsusc.2007.04.011

[17] J. Zhang, Z. L. Wang, Z. M. Wang, "Chemical analysis of the initial corrosion layer on pipeline steels in simulated $\mathrm{CO}_{2}$-enhanced oil recovery brines", Corros. Sci, vol. 65,Dec. 2012, pp. 397-404, doi:10.1016/j.corsci.2012.08.045. 